\title{
Application of entropy measurement technique in grey based Taguchi method for optimization of MIG welding process parameters
}

\author{
Rani Jatav ${ }^{1^{*}}$, Vedansh Chaturvedi ${ }^{2}$ \\ ${ }^{1,2}$ Department of Mechanical Engineering, Madhav Institute of Technology \& Science, Gwalior, 474005, Madhya Pradesh, INDIA \\ "Corresponding Author: e-mail: ${ }^{1 *}$ rani.mech48@gmail.com, Tel.no.08989273208
}

\begin{abstract}
We seldom realized that without this form of metal work, many structures would cease to be in existence. A skilled journeymen welder joins metal in such a way that it is not able to be parted unless it is cut. Welding is an absolutely essential technique used in various industries like automotive industry, construction industry as well as in the aviation industry. Hence welding process parameters are required to be optimized for their responses or welding characteristics. This study incorporates entropy measurement technique based on grey Taguchi method to analyze multiple quality characteristic optimization of metal inert gas welding of low carbon steel plates. For this study, four control variables are selected current, voltage, gas flow rate and wire feed rate and analysing their effect on the four quality characteristics ultimate tensile strength, elongation \%, bending strength and hardness of the weldments have been investigated in this paper. In order to optimize the multiple quality characteristic of the MIG welding, grey relational analysis coupled with entropy measurement method has been employed. Using entropy measurement method, value of weight corresponding to each quality characteristic has been assigned, so that the importance can be properly determined. Using the theory of grey relational analysis, these have been accumulated to calculate the overall grey relational grade. Signal to Noise ratio ( $\mathrm{S} / \mathrm{N}$ ratio) is applied to find the optimal parameter setting. To determine the contribution of MIG welding process parameters, Analysis of variance (ANOVA) on grey relational grade has been calculated. The confirmatory test also has been done for verifying the results. A foresaid methodology has been found fruitful in the cases where simultaneous optimization of huge number of responses is required.
\end{abstract}

Keywords: Metal Inert Gas (MIG) Welding, Grey-Taguchi Method, Entropy Measurement Technique, Analysis of variance (ANOVA), S-N ratio.

DOI: http://dx.doi.org/10.4314/ijest.v8i3.3

\section{Introduction}

Metal inert gas (MIG) welding is an arc welding process which plays an important role in manufacturing. So, manufacturer does usually face many problems to control the input process parameters to get the desired quality weld. In order to have good knowledge of the MIG welding process, it is essential to find out accurate input-output relationship of the parameters. MIG welding is a complicated process involving multiple variables. Weld quality depends on various input process parameters, such as welding speed, voltage, current, wire feed rate, torch angle, nozzle plate distance, gas flow rate, electromagnetic force, surface tension of the molten metal etc. The task of researchers in the field of development of welding process seems to be convinced i.e. to increase the productivity of the welding process while maintaining or even improving the quality of weld. Various investigators had developed several methods to predict the parameter in MIG welding. This method included statistical, theoretical studies etc. Theoretical studies of complex physical problem like MIG welding process are made depending on number of assumptions. So to make the model simpler, it is essential to find the input-output relationship accurately. Realizing the difficulties associated with the theoretical studies, many researchers have tried to establish input output relationship of process through statistical analysis of the experimental data. Some of them investigations are given below. 
Wu (1992) has developed the three dimensional model for convection and heat transfer in MIG weld pools and solved by using the finite difference technique. Murugan and Parmar (1994) formulated a mathematical equation of four factors, five level factorial techniques to predict the geometry of the weld bead; they used F-test and T-test for adequacy and significance. Tay and Butler (1997) used neural network technology for modelling and optimizing the welding process. Kim and Basu (1999) developed unsteady two dimensional axis-symmetric model for investigating the heat and fluid flow in the weld pool and also found the bead geometry and the velocity and temperature profile. Suban and Tusek (2001) determined the influence of shielding medium which is used on the quantity of the filler material melted (melting rate), they showed the comparison between melting rate in welding with cored wire and solid wire, and also described the mathematical model which predict the influence of the wire extension length on melting rate and concluded that, there is higher melting rate in welding with core wire as compare to that of solid wire. The effect of shielded medium used on the melting rate is negligible. Tusek et al. (2001) described the welding of tailored blanks that was made by different types of materials and concluded that welding of tailored blanks of stainless high alloy and non stainless ferrite steel can be done by melting with filler material and also found that the laser welding of these materials without filler material cannot be performed.

$\mathrm{Hu}$ and Tsai (2007a) developed a unified comprehensive model to simulate the transport phenomena taking place during the gas metal arc welding process, again $\mathrm{Hu}$ and Tsai (2007b) investigated the melting of the electrode, detachment, droplet formation, transfer and impingement on the weld. Ganjigatti et at. (2007) established the relationship between input-output parameters of MIG welding process, they employed regression analysis both globally as well as cluster wise, using full factorial design experiment and concluded that clusterwise regression analysis is better approach than globally approach in predicting the geometry parameters of weld bead. Karadeniz et al. (2007) studied the effect of various gas metal arc welding parameters on the penetration of the weld bead and found that increasing the welding current, increases the depth of penetration of welding. Shahi and Pandey (2008) studied the effects of various process parameters of gas metal arc weld-in and universal GMAW on dilution in single layer stainless steel cladding of low steel plates. James et al. (2009) presented single-line residual stress profile of $8 \mathrm{~mm}$ aluminium plate which was joined by MIG welding and obtained the data by synchrotron diffraction strain scanning. Huang (2010) used three kind of oxide $\mathrm{FeO}_{3}, \mathrm{SiO}_{2}$ and $\mathrm{MgCO}_{3}$ to find the effect of activating flux aided GMAW on geometry, mechanical properties and distortion of the weld bead. Shih et al. (2011) investigated the effect of 8 parameters for aluminium foam plates on micro hardness and bending strength of the weldment by using PCA coupled with Taguchi method and found that current, welding speed, work piece gap are the most important control factor in the process design.

Malviya and Pratihar (2011) used particle swarm optimization (PSO) technique for tuning of neural network for carrying out both forward and reverse mapping of MIG welding process. They found four approaches in which first and second approach deal with tuning of multi-layer-feed-forward and radial basis function neural network, and third and forth relate to a back-propagation algorithm used with particle swarm optimization (PSO) to tune radial basis function of neural net-work. Abbasi et al. (2011) investigated the effect of increased pressure on MIG welding- they observed the variation of weld penetration on different process parameters combinations. Scotti et al. (2012) studied the metal transfer in solid wire MIG welding with the used of laser shadowgraph system with synchronized electrical signal and high speed filming found the new mode and their particular characteristics for completeness. Patel and Chaudhary (2013) used the Design of Experiment method and grey relational analysis for optimizing the MIG and TIG welding parameters, they also used ANOVA for calculating quality characteristics. Sreeraj et al. (2013) presented an experimental study to optimize various input process parameters to found the optimum dilution in stainless steel cladding of low-carbon steel plates which was welded by arc welding. Experiments were performed based on central composite rotatable design with full replication technique and using the multiple regression method with PSO technique to optimize the parameters to get minimal dilution. Mahdi et al. (2014) investigated the effect of welding parameter on the corrosion and mechanical properties of AA6061 T6.

In the Taguchi approach is to minimize the variation in outputs but it cannot solve multiple objective optimizations problems. This can be appropriately solved by grey based Taguchi method. This approach converts a multiple response method optimization problem into a single response optimization state. Another challenging situation in multiple objective optimizations is that, all response variables may not be equally important. For example in case of cladding, bead width is a more important feature compared to bead penetration. In case of butt welding penetration is more significant compared to reinforcement. So, depending on the relative importance of the different response feature, different weight value should be assigned but there is no specific rule for assigning the weights of responses. This problematic situation can be easily overcome by Entropy measurement technique.

Entropy measurement technique was proposed by Wen et al. (1998). It is a method in which we can evaluate individual response weights on the basis of entropy of the whole process. Datta et al. (2009) applied the entropy measurement technique with principal component analysis (PCA) in submerged arc welding for optimizes bead geometry parameter. Moshat et al. (2010) used entropy measurement for the optimization of CNC milling process parameters. Gupta et al. (2014) was also used Entropy Measurement method for optimizing the process parameters of friction stir welding of aluminium alloy.

In the present paper, an attempt has been made to develop a methodology for solving a multi response optimization problem in MIG welding. The response data are tensile strength, elongation \%, bending strength and hardness have been optimize. Entropy measurement technique has been used to estimate the individual response weights. Finally, grey based Taguchi method has been employed for optimization. Result has been verified through confirmatory test.

In order to optimize the quality characteristics, the present investigation has been made in the following sequence. 
- Selection of material for base metal.

- Identify the quality characteristics and welding process parameters to be evaluated.

- Find out the range and levels of the selected process parameters

- Select the orthogonal array.

- Conduct the experiment as per the selected orthogonal array.

- Record the quality characteristics.

- Normalizing the quality characteristics.

- Perform the entropy measurement method based on grey Taguchi and calculate the grey relational grade

- Find the optimal conditions for MIG welding.

- Identify the significant factors.

- Check the adequacy of the developed models.

- Conduct the confirmation test to verify the optimal welding parameters.

\section{Methodology for optimization}

Assuming, the number of experimental runs on the basis of Taguchi's Orthogonal Array (OA) design is $m$, and the number of quality characteristics is $n$. The experimental results can be expressed by the following series: $X_{1}, X_{2}, X_{3}, \ldots \ldots \ldots ., X_{i}, \ldots ., X_{m}$ Here,

$$
\begin{aligned}
& X_{1}=\left\{X_{1}(1), X_{1}(2) \ldots \ldots \ldots X_{1}(k) \ldots . . X_{1}(n)\right\} \\
& X_{i}=\left\{X_{i}(1), X_{i}(2) \ldots \ldots \ldots X_{i}(k) \ldots . . X_{i}(n)\right\} \\
& X_{m}=\left\{X_{m}(1), X_{m}(2) \ldots \ldots \ldots X_{m}(k) \ldots . . X_{m}(n)\right\}
\end{aligned}
$$

Here, $X_{i}$ represents the result of $i^{\text {th }}$ experimental and is called the comparative sequence in grey relational analysis.

Let, $X_{0}$ be the reference sequence:

Let, $X_{0}=\left\{X_{0}(1), X_{0}(2) \ldots \ldots \ldots X_{0}(k) \ldots . . X_{0}(n)\right\}$

The value of the elements in the reference sequence means the optimal value of the corresponding quality characteristic. $X_{0}$ and $X_{i}$ both includes $n$ elements, and $X_{0}(k)$ and $X_{i}(k)$ represent the numeric value of $k^{\text {th }}$ element in the reference sequence and the comparative sequence, respectively, $k=1,2, \ldots \ldots ., n$. The following illustrates the proposed parameter optimization procedures in detail.

\section{Step 2.1: Normalization of the quality characteristic}

When the range of the series is too large or the optimal value of a quality characteristic is too vast, it will cause the influence of some factors to be ignored. The original responses data must be normalized to eliminate such effect. There are three different types of data normalization according to whether we require the LB (lower the better), NB (nominal-the-best) the HB (higher the better). This process is known as grey relational generation (Tosun, 2006; Tsao, 2009). The normalization is taken by the following equations.

(a) LB (lower-the-better)

$$
X_{i}^{*}(k)=\frac{\min X_{i}(k)}{X_{i}(k)}
$$

(b) HB (higher-the-better)

$$
X_{i}^{*}(k)=\frac{X_{i}(k)}{\max X_{i}(k)}
$$

(c) NB (nominal-the-best)

$$
X_{i}^{*}(k)=\frac{\min \left\{X_{i}(k), X_{0 b}(k)\right\}}{\max \left\{X_{i}(k), X_{0 b}(k)\right\}}
$$


$\begin{aligned} i & =1,2, \ldots \ldots . ., m \\ & \text { Here } \\ k & =1,2, \ldots \ldots . ., n\end{aligned}$

$X_{i}^{*}(k)$ is the normalized data of the $k^{\text {th }}$ element in the $i^{\text {th }}$ sequence.

$X_{0 b}(k)$ is the required value of the $k^{\text {th }}$ quality characteristic. After data normalization, the value of $X_{i}^{*}(k)$ will be between 0 and

1. The series $X_{i}^{*}, i=1,2,3, \ldots \ldots . ., m$. can be view as the comparative sequence used in the grey relational analysis.

\section{Step 2.2: Calculation of the individual grey relational grades}

(1) Calculation of the individual grey relational coefficients.

To calculate the grey relational coefficient between $X_{0}(k)$ and $X_{i}(k)$, Use the following equation:

$$
r_{0, i}(k)=\frac{\Delta_{\min }+\xi \triangle_{\max }}{\Delta_{0, i}(k)+\xi \triangle_{\max }}, \quad i=1,2, \ldots \ldots \ldots . ., m, k=1,2, \ldots . ., n .
$$

Here, $r_{0, i}(k)$ is the relative difference of $k^{\text {th }}$ element between sequence $X_{i}$ and the comparative sequence $X_{0}$ (which is also called grey relational grade), and $\Delta_{0, i}(k)$ is the absolute value of difference between $X_{0}(k)$ and $X_{i}(k)$.

Where $\Delta_{0 i}=\left\|X_{0}(k)-X_{i}(k)\right\|=$ difference of the absolute value $X_{0}(k)$ and $X_{i}(k) ; \phi$ is the distinguishing coefficient $\quad 0 \leq \psi \leq 1 \quad ; \quad \Delta_{\min }=\forall j^{\min } \in i \forall k^{\min }\left\|X_{0}(k)-X_{i}(k)\right\|=$ the smallest value of $\Delta_{0 i} ; \quad$ and $\Delta_{\max }=\forall j^{\max } \in i \forall k^{\max }\left\|X_{0}(k)-X_{i}(k)\right\|=$ largest value of $\Delta_{0 i}$

Note that $\xi$ is called the distinguishing coefficient, and its value is in between 0 to 1 . In general it is set to 0.5, (Deng, 1989).

\section{Step 2.3: Calculation of the weight of each quality characteristics by entropy method}

In information theory, entropy is computed of how disordered a system is. As applying the concept of entropy to weight measurement, an attribute with a large entropy means it has a great diversity to responses so the attribute has more significant effects to the response. In recent times, entropy measurement method is used to decide the weights in grey relational analysis. According to the definition proposed by Wen et al. (1998), the mapping function $f_{i}:[0,1] \rightarrow[0,1]$ used in entropy should satisfy three conditions: (1) $f_{i}(0)=0$ (2) $f_{i}(x)=f_{i}(1-x)$ and (3) $f_{i}(x)$ is monotonic increasing in the range $x \in(0,0.5)$. Thus, the following function $w_{e}(x)$ can be used as the mapping function in entropy measure.

$$
w_{e}(x)=x \cdot e^{(1-x)}+(1-x) e^{x}-1
$$

The maximum value of this function occurs at $x=0.5$, and the value is $e^{0.5}-1=0.6487$. In order to get the mapping result in the range $[0,1]$, Wen et al. (1998) defined new entropy:

$$
W \equiv \frac{1}{\left(e^{0.5}-1\right)} \sum_{i=1}^{m} w_{e}\left(x_{i}\right)
$$

Assume there is a sequence $\epsilon_{i}=\left\{r_{i}(1), r_{i}(2), \ldots \ldots \ldots \ldots \ldots \ldots, r_{i}(n)\right\}$. Where, $r_{i}(j)$ is the grey relational coefficient. Note that $i=1,2$, $m ; j=1,2$,

The steps for weight calculation are as follows (Wen et al., 1998).

(a) Calculation of the $D_{j}$ (sum of the grey relational coefficient in all sequences for each quality characteristic)

$$
D_{j}=\sum_{i=1}^{m} r_{i}(j), j=1,2, \ldots \ldots \ldots, n \text {. }
$$

(b) Evaluation of the normalized coefficient

$$
k=\frac{1}{\left(e^{0.5}-1\right) \times m}=\frac{1}{0.6487 \times m}
$$

(c) Calculation of the entropy of each quality characteristics 


$$
e_{j}=k \sum_{i=1}^{m} w_{e}\left(\frac{r_{i}(j)}{D_{j}}\right), \quad j=1,2, \ldots \ldots \ldots \ldots \ldots . . ., n .
$$

Here, $w_{e}(x)=x \cdot e^{(1-x)}+(1-x) e^{x}-1$

(d) Calculation of the sum of entropy

$$
E=\sum_{j=1}^{n} e_{j}
$$

(e) Calculation of the weight of each response parameters:

$$
w_{j}=\frac{1}{n-E} \cdot \frac{\left[1-e_{j}\right]}{\sum_{j=1}^{n} \frac{1}{n-E} \cdot\left[1-e_{j}\right]}, \text { here, } j=1,2, \ldots \ldots \ldots \ldots \ldots, n .
$$

\section{Step 2.4; Calculation of the overall grey relational grade}

After the grey relational coefficient calculation, the grey relational grade is determined by:

$$
\Gamma_{0, i}=\sum_{k=1}^{n} w_{k} r_{0, i}(k), \quad i=1,2, \ldots \ldots \ldots \ldots \ldots \ldots . ., m .
$$

The purpose of the analysis of variance (ANOVA) is to determine which input parameters significantly affect the performance of the output parameters. This is accomplished by separating the total variability of the grey relational grades, which is calculated by the sum of the squared deviation from the total mean of the grey relational grade into the contribution of the each welding parameters and the error. In addition Fisher's F-Test can also be used to determine which input parameters have a significant effect on the performance characteristics. (Fisher, 1925; Patil and Waghmare, 2013; Joshi et al., 2014).

\section{Experimentation and data collection}

MIG welding on single pass type has been carried out on low carbon steel plates (thickness $6 \mathrm{~mm}$ ) as per Taguchi $\mathrm{L}_{9}$ OA design with 9 combinations of voltage, current, gas flow rate and wire feed rate. The size of the workpeice used in the experiment is $150 \times 30 \times 6 \mathrm{~mm}^{3}$. The specimens were prepared with double V-shaped groove as shown in Figure 1. Where groove angle, root face and root gap were $60^{\circ}, 2 \mathrm{~mm}$ and $2 \mathrm{~mm}$ respectively. As the butt joint is prepared by welding two plates along the width. 27 specimens were prepared. The experiments were performed on the MIG welding setup manufactured by "Technology Promoters (I) Pvt. Ltd. MIG 400" shown in Figure 2 (a). Copper coated mn-si double dioxidized wire of diameter 1.2mm (AWS/SFA 5.1893 ER70S6) has been used during experiment. $\mathrm{CO}_{2}$ is used as the shielding gas in all the experiments. To find out the chemical composition of the work piece, optical emission spectroscopy (OES) has been done. Rockwell hardness tester is used to set up the hardness of the fusion zone shown in Figure 2(b). The hardness of the weld joint is taken as the average of the 3 value along the centre line of fusion zone. The universal testing machine of capacity $60,000 \mathrm{kgf}$ is used to carry out tensile and bending test in this experiment (make: - Fuel instrument \& engineers PVT. LTD.). Shown in Figure 2(c). Some of welded plates were machined to the required shape to conduct the tensile test as shown in figure 3(a). Composition of wire and parent metal is shown in Table 1.Total 9 test sample from each of weldment produced by $\mathrm{L}_{9}$ experiment. The process parameters and selected level of experiment is shown in Table 2. The experiments carried out and testing done on each specimen and data were recorded as per Table 3.

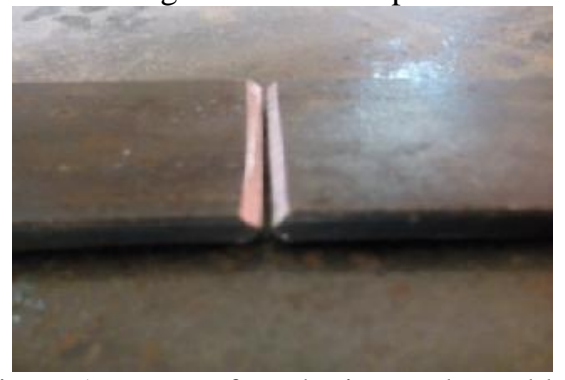

Figure 1: Image of work piece to be welded

Table 1: Composition of base metal and filler material

\begin{tabular}{lcccccc}
\hline Designation & $\mathrm{C} \%$ & $\mathrm{Si} \%$ & $\mathrm{Mn} \%$ & $\mathrm{P} \%$ & $\mathrm{~S} \%$ & $\mathrm{Cu} \%$ \\
\hline Parent metal & 0.023 & 1.570 & 0.254 & 0.013 & 0.012 & 0.007 \\
Filler metal & 0.090 & 0.800 & 1.560 & 0.025 & 0.025 & 0.500
\end{tabular}

Table 2: Domain of Experiment (limits of factor) 


\begin{tabular}{|c|c|c|c|c|c|}
\hline Parameters & Unit & Notation & Level 1 & Level 2 & Level 3 \\
\hline Current & Amp. & A & 50 & 100 & 150 \\
\hline Voltage & Volt. & V & 20 & 25 & 30 \\
\hline Gas flow rate & Lit./min & Gf & 10 & 12 & 15 \\
\hline Wire feed & $\mathrm{m} / \mathrm{min}$ & Wf & 8 & 10 & 12 \\
\hline
\end{tabular}

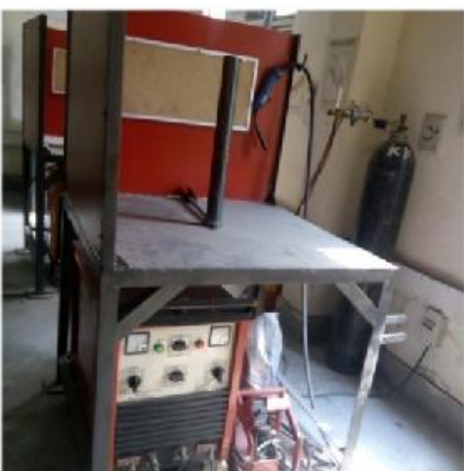

(a)

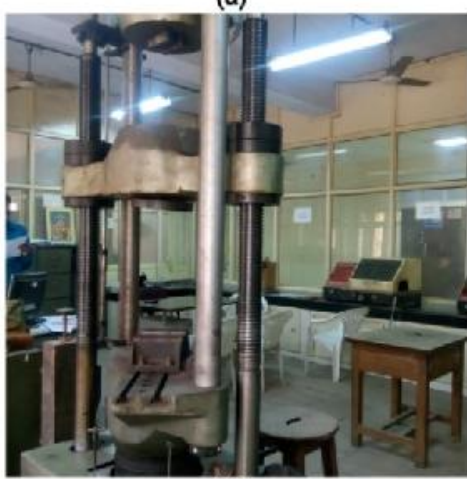

(c)

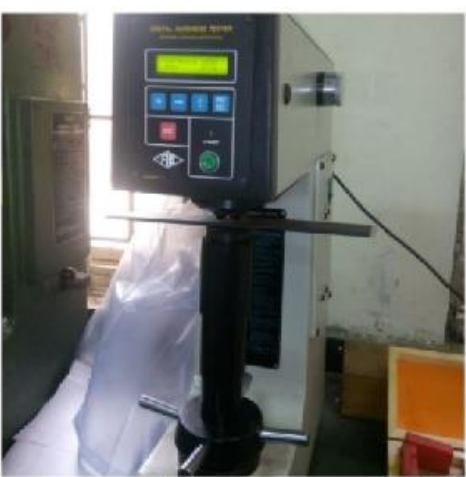

(b)

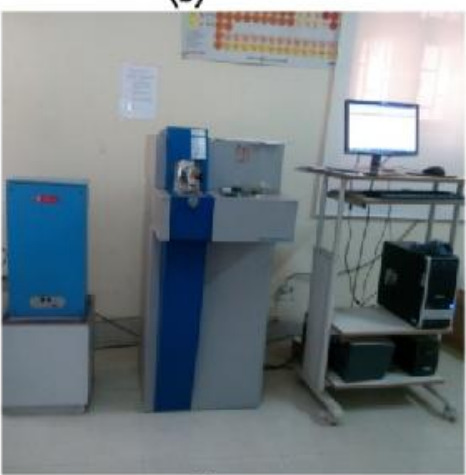

(d)

Figure 2: (a) MIG welding setup, (b) Rockwell Hardness tester, (c) Universal testing machine and (d) Metal spectrometer.

Table 3: Response data as per Taguchi $\mathrm{L}_{9} \mathrm{OA}$ design

\begin{tabular}{|c|c|c|c|c|c|c|c|c|c|c|}
\hline \multirow{3}{*}{ S. No. } & \multicolumn{4}{|c|}{$\mathrm{L}_{9} \mathrm{OA}$} & \multicolumn{6}{|c|}{ Response value related to weld quality } \\
\hline & \multirow[t]{2}{*}{ A } & \multirow[t]{2}{*}{$\mathrm{V}$} & \multirow{2}{*}{ Gf } & \multirow{2}{*}{ Wf } & \multirow{2}{*}{$\begin{array}{c}\text { Ultimate } \\
\text { Tensile } \\
\text { Strength } \\
(\mathrm{MPa})\end{array}$} & \multirow{2}{*}{$\begin{array}{c}\text { Elongation } \\
(\%)\end{array}$} & \multirow{2}{*}{$\begin{array}{c}\text { Bending } \\
\text { Strength } \\
\text { (KN) }\end{array}$} & \multicolumn{3}{|c|}{$\begin{array}{c}\text { Hardness } \\
\text { (HRB) }\end{array}$} \\
\hline & & & & & & & & Test 1 & Test 2 & Test 3 \\
\hline 1 & 1 & 1 & 1 & 1 & 420 & 9.286 & 5.370 & 72.1 & 75.2 & 79.4 \\
\hline 2 & 1 & 2 & 2 & 2 & 365 & 7.910 & 4.440 & 73.2 & 70.1 & 77.3 \\
\hline 3 & 1 & 3 & 3 & 3 & 373 & 8.571 & 5.550 & 75.5 & 69.4 & 79.4 \\
\hline 4 & 2 & 1 & 2 & 3 & 334 & 6.382 & 5.450 & 74.2 & 68.2 & 70.4 \\
\hline 5 & 2 & 2 & 3 & 1 & 315 & 6.429 & 5.850 & 75.4 & 71.6 & 66.7 \\
\hline 6 & 2 & 3 & 1 & 2 & 360 & 7.320 & 5.665 & 78.6 & 75.4 & 60.2 \\
\hline 7 & 3 & 1 & 3 & 2 & 378 & 7.000 & 4.560 & 79.4 & 77.6 & 74.5 \\
\hline 8 & 3 & 2 & 1 & 3 & 404 & 9.132 & 4.110 & 68.1 & 72.3 & 70.6 \\
\hline 9 & 3 & 3 & 2 & 1 & 424 & 22.143 & 5.340 & 78.8 & 73.6 & 69.1 \\
\hline
\end{tabular}



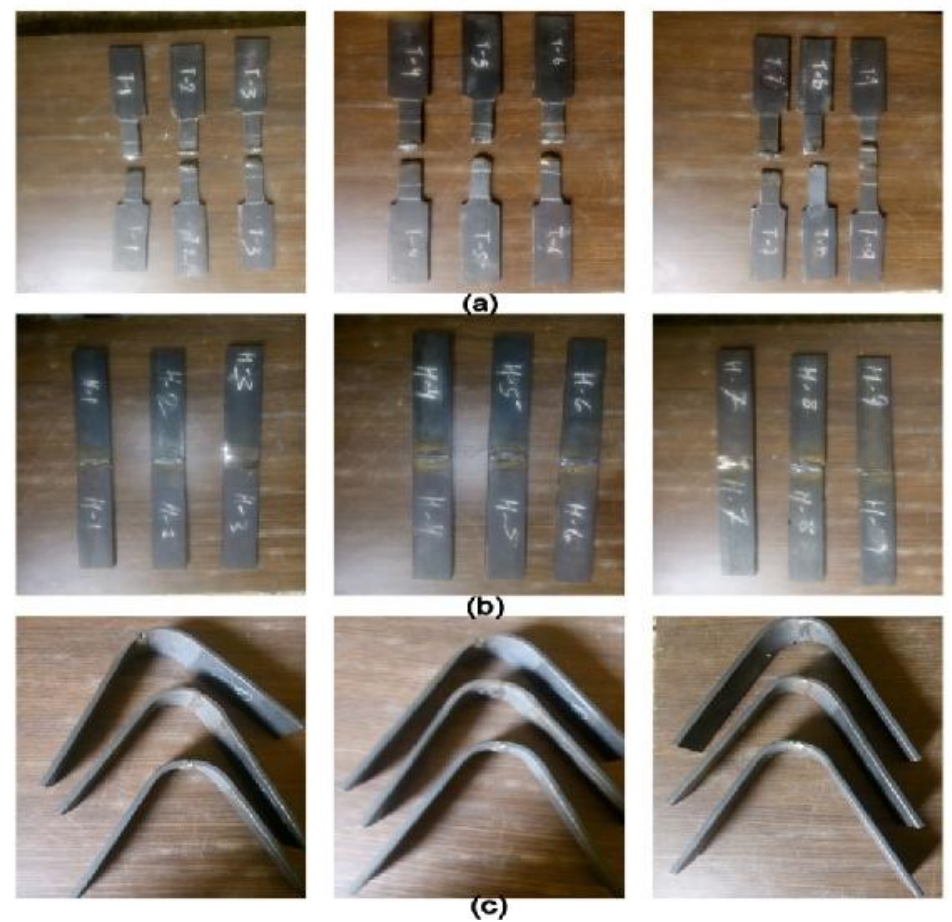

Figure 3: (a) Tensile and elongation specimen (b) Hardness specimen and (c) Bending strength specimen

\section{Data analysis and optimization}

Experimental data have been normalized using Equation (2). For Tensile strength, Elongation, Hardness and Bending strength HB criteria have been selected. The normalized data are shown in Table 4.

Table 4: Data pre-processing of each performance characteristic (Normalization of experiment data)

\begin{tabular}{|c|c|c|c|c|}
\hline \multirow{2}{*}{ S. No. } & \multicolumn{4}{|c|}{ Normalizing data } \\
\cline { 2 - 5 } & $\begin{array}{c}\text { Ultimate Tensile } \\
\text { Strength }\end{array}$ & Elongation & $\begin{array}{c}\text { Bending } \\
\text { Strength }\end{array}$ & Hardness \\
\hline $\begin{array}{c}\text { Ideal } \\
\text { condition }\end{array}$ & 1.0000 & 1.0000 & 1.0000 & 1.0000 \\
\hline 1 & 0.9905 & 0.4193 & 0.9179 & 0.9793 \\
\hline 2 & 0.8608 & 0.3572 & 0.7589 & 0.9529 \\
\hline 3 & 0.8797 & 0.3870 & 0.9487 & 0.9690 \\
\hline 4 & 0.7877 & 0.2882 & 0.9316 & 0.9192 \\
\hline 5 & 0.7429 & 0.2903 & 1.0000 & 0.9231 \\
\hline 6 & 0.8490 & 0.3305 & 0.9675 & 0.9257 \\
\hline 7 & 0.8915 & 0.3160 & 0.7795 & 1.0000 \\
\hline 8 & 0.9528 & 0.4124 & 0.7026 & 0.9115 \\
\hline 9 & 1.0000 & 1.0000 & 0.9128 & 0.9568 \\
\hline
\end{tabular}


Table 5: Quality loss estimates

\begin{tabular}{|c|c|c|c|c|}
\hline \multirow[b]{2}{*}{ S. No. } & \multicolumn{4}{|c|}{$\left({ }_{0 i}\right)$} \\
\hline & $\begin{array}{c}\text { Ultimate Tensile } \\
\text { Strength }\end{array}$ & Elongation & $\begin{array}{l}\text { Bending } \\
\text { Strength }\end{array}$ & Hardness \\
\hline 1 & 0.0095 & 0.5807 & 0.0821 & 0.0207 \\
\hline 2 & 0.1392 & 0.6428 & 0.2411 & 0.0471 \\
\hline 3 & 0.1203 & 0.6130 & 0.0513 & 0.0310 \\
\hline 4 & 0.2123 & 0.7118 & 0.0684 & 0.0808 \\
\hline 5 & 0.2571 & 0.7097 & 0.0000 & 0.0769 \\
\hline 6 & 0.1510 & 0.6695 & 0.0325 & 0.0743 \\
\hline 7 & 0.1085 & 0.6846 & 0.2205 & 0.0000 \\
\hline 8 & 0.0472 & 0.5876 & 0.2974 & 0.0885 \\
\hline 9 & 0.0000 & 0.0000 & 0.0872 & 0.0432 \\
\hline
\end{tabular}

Using the Equation (4), the grey relational coefficient have been calculated which is shown in Table 6. The sum of grey relational coefficients $D_{j}, j=1,2,3,4$ for quality indices, have been calculated using Equation (7). These are shown in Table 7. The value of the normalized coefficient has been calculated using Equation (8). In the present case $m=9$.Calculated value of the normalized coefficient becomes $k=0.1713$

Table 6: Calculation of individual grey relational coefficients

\begin{tabular}{|c|c|c|c|c|}
\hline \multirow{2}{*}{ S. No. } & \multicolumn{4}{|c|}{ Individual grey relational coefficients } \\
\cline { 2 - 5 } & $\begin{array}{c}\text { Ultimate Tensile } \\
\text { Strength }\end{array}$ & Elongation & $\begin{array}{c}\text { Bending } \\
\text { Strength }\end{array}$ & Hardness \\
\hline 1 & 0.9311 & 0.3800 & 0.6442 & 0.6810 \\
\hline 2 & 0.4800 & 0.3564 & 0.3814 & 0.4840 \\
\hline 3 & 0.5165 & 0.3673 & 0.7435 & 0.5877 \\
\hline 4 & 0.3770 & 0.3333 & 0.6849 & 0.3536 \\
\hline 5 & 0.3332 & 0.3340 & 1.0000 & 0.3650 \\
\hline 6 & 0.4597 & 0.3471 & 0.8206 & 0.3730 \\
\hline 7 & 0.5422 & 0.3422 & 0.4028 & 1.0000 \\
\hline 8 & 0.7314 & 0.3772 & 0.3333 & 0.3330 \\
\hline 9 & 1.0000 & 1.0000 & 0.6303 & 0.5057 \\
\hline
\end{tabular}

Table 7: calculation of sum of grey relational coefficients

\begin{tabular}{|c|c|c|c|}
\hline \multicolumn{3}{|c|}{ Sum of grey relational coefficient of each principal components $\left(\mathrm{D}_{\mathrm{j}}\right)$} \\
\hline $\begin{array}{c}\text { Ultimate Tensile } \\
\text { Strength }\end{array}$ & Elongation & Bending Strength & Hardness \\
\hline 5.3711 & 3.8375 & 5.6410 & 4.6831 \\
\hline
\end{tabular}


The values of $\left(\frac{r_{i}(j)}{D_{j}}\right)$ and $k \times w_{e}\left(\frac{r_{i}(j)}{D_{j}}\right)$ for the four quality indices related to weld characteristics have been furnished in Table 8 and 9 , respectively.

Table 8: Calculation of $\left(\frac{r_{i}(j)}{D_{j}}\right)$

\begin{tabular}{|c|c|c|c|c|}
\hline \multirow{2}{*}{ S. No. } & \multicolumn{4}{|c|}{$\left(\frac{r_{i}(j)}{D_{j}}\right)$} \\
\cline { 2 - 5 } & $\begin{array}{c}\text { Ultimate Tensile } \\
\text { Strength }\end{array}$ & Elongation & $\begin{array}{c}\text { Bending } \\
\text { Strength }\end{array}$ & Hardness \\
\hline 1 & 0.1733 & 0.0990 & 0.1142 & 0.1454 \\
\hline 2 & 0.0894 & 0.0926 & 0.0676 & 0.1034 \\
\hline 3 & 0.0962 & 0.0957 & 0.1318 & 0.1254 \\
\hline 4 & 0.0702 & 0.0868 & 0.1214 & 0.0755 \\
\hline 5 & 0.0620 & 0.0870 & 0.1773 & 0.0784 \\
\hline 6 & 0.0856 & 0.0904 & 0.1455 & 0.0796 \\
\hline 7 & 0.1010 & 0.0892 & 0.0714 & 0.2135 \\
\hline 8 & 0.1362 & 0.0983 & 0.0591 & 0.0711 \\
\hline 9 & 0.1862 & 0.2606 & 0.1117 & 0.1070 \\
\hline
\end{tabular}

Table 9: Calculation of $k \times w_{e}\left(\frac{r_{i}(j)}{D_{j}}\right)$

\begin{tabular}{|c|c|c|c|c|}
\hline \multirow{2}{*}{ S. No. } & \multicolumn{4}{|c|}{$k \times w_{e}\left(\frac{r_{i}(j)}{D_{j}}\right)$} \\
\cline { 2 - 5 } & $\begin{array}{c}\text { Ultimate } \\
\text { Tensile Strength }\end{array}$ & Elongation & $\begin{array}{c}\text { Bending } \\
\text { Strength }\end{array}$ & Hardness \\
\hline 1 & 0.0649 & 0.0408 & 0.0463 & 0.0565 \\
\hline 2 & 0.0373 & 0.0385 & 0.0290 & 0.0424 \\
\hline 3 & 0.0393 & 0.0396 & 0.0521 & 0.0500 \\
\hline 4 & 0.0300 & 0.0364 & 0.0484 & 0.0321 \\
\hline 5 & 0.0268 & 0.0364 & 0.0661 & 0.0330 \\
\hline 6 & 0.0359 & 0.0377 & 0.0565 & 0.0336 \\
\hline 7 & 0.0416 & 0.0373 & 0.0305 & 0.0758 \\
\hline 8 & 0.0536 & 0.0406 & 0.0256 & 0.0304 \\
\hline 9 & 0.0686 & 0.0866 & 0.0454 & 0.0440 \\
\hline
\end{tabular}

Entropy of four quality indexes, have been calculated using Equation (9); the values have been furnished in Table 10. The sum of entropy E has been calculated using Equation (10). The weights of four response features (Table 11) have been calculated using Equation (11). Using Equation (12), the overall grey relational grade has been calculated shown in Table 12. Thus, the multicriteria optimization problem has been converting into a single objective optimization problem using the combination of Taguchi approach with grey relational analyses. Higher is the value of grey relational grade, the equivalent factor combination is said to be nearer to the optimal. 
Table 10: Calculation of $e_{j}$ (entropy of each quality indexes)

\begin{tabular}{|c|c|c|c|}
\hline \multicolumn{4}{|c|}{ Entropy of each quality indexes } \\
\hline $\begin{array}{c}\text { Ultimate Tensile } \\
\text { Strength }\end{array}$ & Elongation & Bending Strength & Hardness \\
\hline 0.3986 & 0.3939 & 0.3999 & 0.3978 \\
\hline
\end{tabular}

Table 11: Calculation of $w_{j}$ (weightage value of each quality characteristics)

\begin{tabular}{|c|c|c|c|}
\hline \multicolumn{4}{|c|}{ Weightage value of each quality indexes } \\
\hline $\begin{array}{c}\text { Ultimate Tensile } \\
\text { Strength }\end{array}$ & Elongation & Bending Strength & Hardness \\
\hline 0.2496 & 0.2515 & 0.2490 & 0.2499 \\
\hline
\end{tabular}

Table 12: Calculation of overall grey relational grade

\begin{tabular}{|c|c|}
\hline S. No. & $\Gamma_{0, i}$ \\
\hline 1 & 0.6586 \\
\hline 2 & 0.4254 \\
\hline 3 & 0.5533 \\
\hline 4 & 0.4368 \\
\hline 5 & 0.5074 \\
\hline 6 & 0.4996 \\
\hline 7 & 0.5716 \\
\hline 8 & 0.4436 \\
\hline 9 & 0.7844 \\
\hline
\end{tabular}

In Figure 4 graphically representation of $\mathrm{S} / \mathrm{N}$ ratio plot for grey relational grade is shown. The $\mathrm{S} / \mathrm{N}$ ratio has been calculated by using HB (higher-the-better) criterion, which is shown in below (Equation 13).

$$
S N(\text { Higher }- \text { the }- \text { better })=-10 \log \left[\frac{1}{t} \sum_{i=1}^{t} \frac{1}{y_{i}^{2}}\right]
$$

Here $t$ is the number of measurements, and $y_{i}$ the measured $i$ th characteristic value i.e. $i$ th quality indicator. With the help of the Figure 4, optimal parametric combination has been determined. The optimal factor setting becomes A3V3GF3WF1 


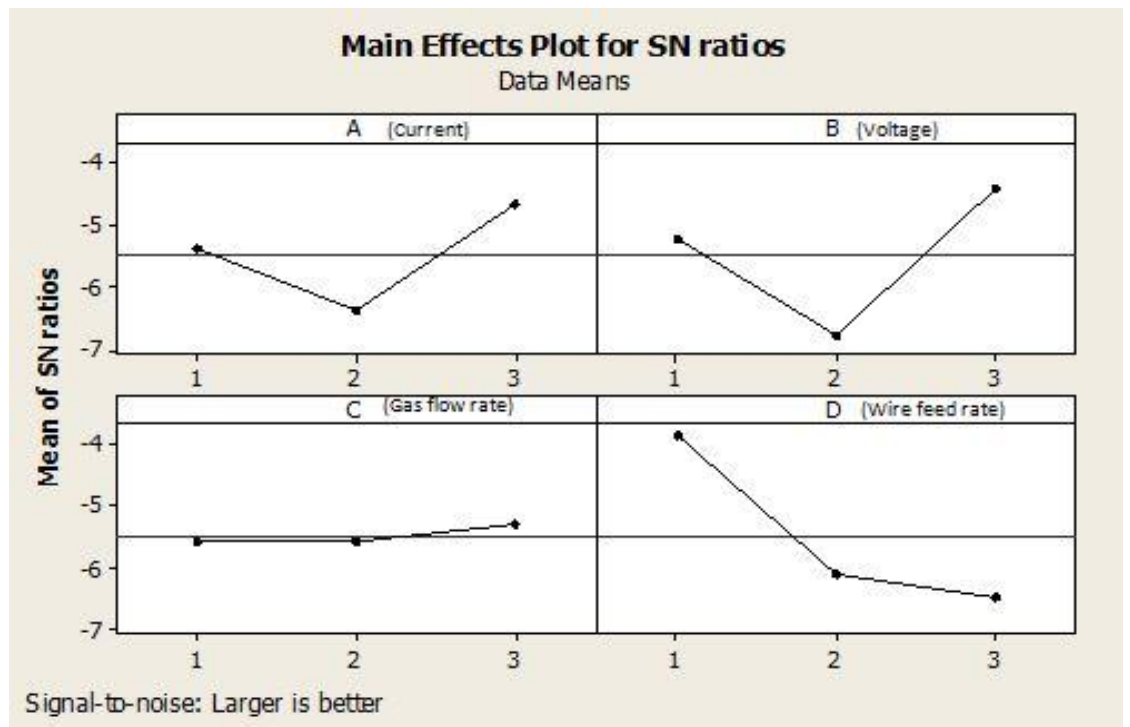

Figure 4: S/N ratio plot for overall grey relational grade

\section{Analysis of variance (ANOVA)}

ANOVA of overall grey relational grade have shown that the important factors influencing overall grey relational grade are current, voltage, gas flow rate and wire feed rate. In order of their significant factor in influencing the overall grey relational grade.

Table 13: Analysis of variance (ANOVA)

\begin{tabular}{|c|c|c|c|c|c|c|}
\hline Factor & DOF & $\begin{array}{c}\text { Sum of } \\
\text { square }\end{array}$ & $\begin{array}{c}\text { Mean of } \\
\text { Variance }\end{array}$ & F-ratio & Sz & $\begin{array}{c}\text { Contribution } \\
\%\end{array}$ \\
\hline $\mathrm{A}$ & 2 & 0.0210 & 0.0105 & 0.0105 & 0.0210 & 18.99 \\
\hline $\mathrm{B}$ & 2 & 0.0362 & 0.0181 & 0.0181 & 0.0362 & 32.73 \\
\hline $\mathrm{C}$ & 2 & 0.0002 & 0.0001 & 0.0001 & 0.0002 & 0.18 \\
\hline $\mathrm{D}$ & 2 & 0.0531 & 0.0265 & 0.0265 & 0.0531 & 48.01 \\
\hline Error & 0 & 0.0001 & & & & 0.09 \\
\hline Total & 8 & 0.1105 & & & & 100 \\
\hline
\end{tabular}

ANOVA table shows that factor $\mathrm{D}$ i.e. is the wire feed rate having maximum percentage of contribution, i.e. $48.01 \%$ Therefore it is most significant parameter for all the responses as the wire give strength to the weld joint so the responses are very much dependent on the feed rate of wire. Whereas factor $\mathrm{C}$, which is gas flow rate is having least percentage of contribution as the inert gas prevent the material reaction with the atmosphere but do not play vital role in quality characteristics of the weld joint in this investigation as compare the other parameters.

In this paper, the multiple quality characteristics are pooled to one grey relational grade, thus the conventional Taguchi method can be used to evaluate the optimal parameter combination. The next step is to predict and confirm the enhancement of quality characteristics using the most favourable parametric combination. Table 14 reflects the satisfactory result of the confirmatory experiment. 
Table 14: Result for confirmatory experiment

\begin{tabular}{|c|c|c|}
\hline \multirow{2}{*}{} & \multicolumn{2}{|c|}{ Optimal setting } \\
\cline { 2 - 3 } Level of factors & A3V3GF3WF1 & A3V3GF3WF1 \\
\hline $\begin{array}{c}\text { S/N ratio of overall grey } \\
\text { relational grade }\end{array}$ & -1.8307 & -1.8239 \\
\hline $\begin{array}{c}\text { Overall grey relational } \\
\text { grade }\end{array}$ & 0.8099 & 0.8106 \\
\hline
\end{tabular}

\section{Conclusion}

The attempt has been made to optimize MIG welding process parameters for low carbon steel using entropy measurement technique. There are four responses are considered for this study i.e. tensile strength, Elongation, Bending strength and Hardness. Observation of data has been carried out according to $\mathrm{L}_{9}$ orthogonal array experiment run. As all responses need to be higher therefore they are normalized based on "higher are better" criteria of Grey Taguchi method. Subsequently entropy weightage of each response was calculated and overall grey relational grade was found for each experimental run. Predicted optimal parameter setting (A3V3Gf3Wf1) was formed in Figure 4 and analysis of variance (ANOVA) table shows the most significant parameters i.e. $\mathrm{D}$ (wire feed rate) having maximum percentage contribution. The confirmation test was carried out based on predicted optimal parameters settings and grey relational grade was found to be 0.8106 and $\mathrm{S} / \mathrm{N}$ ratio -1.8239 , which proves the successful implementation of entropy measurement technique for optimization of process parameter of MIG welding.

\begin{tabular}{|c|c|c|c|c|c|}
\hline \multicolumn{6}{|l|}{ Notations } \\
\hline MIG: & Metal Inert Gas & OA : & Orthogonal Array & PCA : & Principal component analysis \\
\hline ANOVA : & Analysis of variance & C.F: & Correction factor & $\mathrm{S} / \mathrm{N}:$ & Signal to noise ratio \\
\hline DOF : & Degree of freedom & HB : & Higher the better & LB : & Lower the better \\
\hline $\mathrm{T}$ & Total of all result & N Total no. of experiments & \multicolumn{3}{|c|}{ Total no. of experiments } \\
\hline C.F & Correction factor & \multicolumn{4}{|c|}{$X_{Y 1,} X_{Y 2,} X_{Y 3}$ Values of result of each level (i.e. 1, 2, 3) of parameters $Y$. } \\
\hline $\mathrm{V}_{\mathrm{Y}}$ & Variance of parameter $\mathrm{Y}$ & \multicolumn{4}{|c|}{$X_{i} \quad$ Value of result of each experiments $(i=1$ to 9$)$} \\
\hline $\mathrm{V}_{\mathrm{e}}$ & Error of variance & \multicolumn{4}{|c|}{$\mathrm{N}_{\mathrm{Y} 1}, \mathrm{~N}_{\mathrm{Y} 2}, \mathrm{~N}_{\mathrm{Y} 3}$ Repeating $\mathrm{n}$. of each level $(1,2,3)$ of parameter $\mathrm{Y}$} \\
\hline $\mathrm{S}_{\mathrm{Y}}$ & \multicolumn{5}{|c|}{ Sum of the squares of due to parameters $\mathrm{Y}(\mathrm{Y}=\mathrm{A}, \mathrm{B}, \mathrm{C}, \mathrm{D})$} \\
\hline $\mathrm{S}_{\mathrm{T}}$ & \multicolumn{2}{|c|}{ Total sum of squares to total variance $\quad S_{e}$} & $\mathrm{~S}_{\mathrm{e}}$ & \multicolumn{2}{|c|}{ Sum of square of error terms } \\
\hline$f_{Y}$ & \multicolumn{2}{|c|}{ Degree of freedom (D.O.F) of parameter Y } & $\mathrm{f}_{\mathrm{T}}$ & \multicolumn{2}{|c|}{ Total degree of freedom (D.O.F) } \\
\hline$f_{e}$ & \multicolumn{2}{|c|}{ Error of degree of freedom (D.O.F) } & $\mathrm{F}_{\mathrm{Y}}$ & \multicolumn{2}{|c|}{ F-ratio of parameter of $\mathrm{Y}$} \\
\hline$S_{\mathrm{Y}}{ }^{\prime}$ & \multicolumn{2}{|c|}{ Pure sum of square } & $\mathrm{C}_{\mathrm{Y}}$ & \multicolumn{2}{|c|}{ Percentage $(\%)$ of contribution of parameter $\mathrm{Y}$} \\
\hline $\mathrm{C}_{\mathrm{e}}$ & \multicolumn{2}{|c|}{ Percentage $(\%)$ of contribution of error term } & C.F & \multicolumn{2}{|c|}{$\mathrm{T}^{2} / \mathrm{N}$} \\
\hline $\mathrm{S}_{\mathrm{Y}}$ & \multicolumn{2}{|c|}{$\left(\mathrm{X}_{\mathrm{Y} 1}^{2} / \mathrm{N}_{\mathrm{Y} 1}+\mathrm{X}_{\mathrm{Y} 2}{ }^{2} / \mathrm{N}_{\mathrm{Y} 2}+\mathrm{X}_{\mathrm{Y} 3}{ }^{2} / \mathrm{N}_{\mathrm{Y} 3}\right)$} & $\mathrm{f}_{\mathrm{Y}}$ & \multicolumn{2}{|c|}{ (No. of levels of parameters Y) -1} \\
\hline$f_{T}$ & \multicolumn{2}{|c|}{ (Total no. of results) -1} & $\mathrm{f}_{\mathrm{e}}$ & \multicolumn{2}{|c|}{$\mathrm{f}_{\mathrm{T}}-\Sigma \mathrm{f}_{\mathrm{y}}$} \\
\hline $\mathrm{V}_{\mathrm{Y}}$ & \multicolumn{2}{|l|}{$\mathrm{S}_{\mathrm{Y}} / \mathrm{f}_{\mathrm{Y}}$} & $\mathrm{S}_{\mathrm{e}}$ & \multicolumn{2}{|c|}{$\mathrm{S}_{\mathrm{T}}-\Sigma \mathrm{S}_{\mathrm{Y}}$} \\
\hline $\mathrm{V}_{\mathrm{e}}$ & \multicolumn{2}{|l|}{$\mathrm{Se} / \mathrm{f}_{\mathrm{e}}$} & $\mathrm{F}_{\mathrm{y}}$ & \multicolumn{2}{|c|}{$\mathrm{V}_{\mathrm{Y}} / \mathrm{V}_{\mathrm{e}}$} \\
\hline $\mathrm{S}_{\mathrm{Y}}$ & \multicolumn{2}{|l|}{$\mathrm{S}_{\mathrm{Y}}-\left(\mathrm{V}_{\mathrm{e}} * \mathrm{f}_{\mathrm{z}}\right)$} & $\mathrm{P}_{\mathrm{z}}$ & \multicolumn{2}{|c|}{$\mathrm{S}_{\mathrm{Y}} / \mathrm{S}_{\mathrm{T}} * 100 \%$} \\
\hline $\mathrm{P}_{\mathrm{e}}$ & \multicolumn{2}{|l|}{$\left(1-\Sigma P_{Y}\right) * 100 \%$} & $\mathrm{~S}_{\mathrm{T}}$ & \multicolumn{2}{|c|}{$\Sigma_{\mathrm{i}=1 \text { to } 9} \mathrm{X}_{\mathrm{i}}^{2}-\mathrm{C}$. } \\
\hline
\end{tabular}

\section{Symbols}

\begin{tabular}{ll}
\multicolumn{1}{c}{$:$} & Absolute value difference \\
$\mathrm{D}_{\mathrm{j}}:$ & Sum of grey relational coefficient \\
$\mathrm{K}:$ & Normalized coefficient \\
$\mathrm{E}:$ & Sum of entropy \\
$\Gamma_{0, \mathrm{i}}:$ & Overall grey relational grade \\
$\mathrm{Wf}:$ & Wire feed rate \\
$\mathrm{Si}:$ & Silicon \\
$\mathrm{P}:$ & Phosphorous \\
$\mathrm{Cu}:$ & Copper
\end{tabular}

$\mathrm{r}_{\mathrm{i}}: \quad$ Grey relational coefficient

$\mathrm{W}_{\mathrm{e}}$ : Weight function

$e_{j}: \quad$ Entropy of quality characteristics

$\mathrm{W}_{\mathrm{j}}$ : Weight of each responses parameters

Gf: $\quad$ Gas flow rate

C : Carbon

Mn : $\quad$ Maganese

S : $\quad$ Sulphur 


\section{Unit}

A: $\quad$ Ampere

KN : $\quad$ Kilo Newton

$\%: \quad$ Percentage $\begin{array}{llcc}\text { V: } & \text { Voltage } & \text { MPa : } & \text { Mega Pascal } \\ \text { HRB : } & \text { Rockwell } & \text { B hardness ( measured on B scale) }\end{array}$

\section{Acknowledgment}

The Author is thankful to "Process and Product Development Centre Agra (U.P)" for granting permission to conduct No. of experiments on MIG welding and testing of the specimen. Their support is valuably acknowledged.

\section{References}

Abbasi. K, Alam. S and Khan. M.I., 2011, An experimental study on the effect of increased pressure on MIG welding arc, International Journal of Applied Engineering Research, Vol. 2, No. 1, pp. 22-27.

Datta S., Nandi G. and Bandyopadhyay A., 2009, Application of entropy measurement technique in grey based Taguchi method for solution of correlated multiple response optimization problems; A case study in welding, Journal of Manufacturing Systems, Vol. 28, No. 2-3, pp. 55-63.

Deng J.L. (1989). Introduction to grey system theory, Journal of Grey System, Vol.1. No.1, 1-24.

Fisher R.A. (1925). Statistical Method for Researcher Workers, Oliver and Boyd; London, U.K.

Ganjigatti J.P., Pratihar D.K. and Choudhury A. R., 2007, Global versus cluster-wise regression analyses for prediction of bead geometry in MIG welding process, Journal of Materials Processing Technology, Vol. 189, Nos. 1-3, pp. 352-366.

Gupta S.K., Pandey K. N. and Kumar R., 2014, Multi-objective optimization of friction stir welding of aluminium alloy using grey relational analysis with entropy measurement method, Nirma University Journal of Engineering and Technology, Vol. 3, No. 1, pp. 29-34.

Hu J. and Tsai H.L., 2007a, Heat and mass transfer on gas metal arc welding Part I: The arc. International Journal of Heat and Mass Transfer, Vol. 50, No. 5-6, pp. 833-846.

Hu J. and Tsai H.L., 2007b, Heat and Mass transfer on gas metal arc welding Part II: The metal, International Journal of Heat and Mass Transfer, Vol. 50, No. 5-6, pp. 808-820.

Huang H.-Y., 2010, Effect of activating flux on the weld joint characteristic in gas metal arc welding, International Journal of Material and Design, Vol. 31, No. 5, pp. 2488-2495.

James M.N., Hughes D.J., Hattingh D.G., Mills G., and Webster P.J., 2009, Residual stress and strain in MIG butt welds in $5083-$ H321 aluminium: As-welded and fatigue cycled, International Journal of Fatigue, Vol. 31, No. 1, pp. 28-40.

Joshi J., Thakkar M. and Vora S., 2014, Parametric optimization of metal inert gas welding and tungsten inert gas welding by using analysis of variance and grey relational analysis, International Journal of Science and Research, Vol 3, pp. 1099-1103.

Karadeniz E., Ozsarac U. and Yildiz C., 2007, The effect of process parameters on penetration in gas metal arc welding processes. Materials and Design, Vol. 28, No. 2, pp. 649-656.

Kim I.S and Basu A., 1999, A mathematical model of heat transfer and fluid flow in the gas metal arc welding process. Journal of Materials Processing Technology, Vol.77, pp. 17-24.

Mahdi E., Eltai E.O. and Rauf A., 2014, The impact of metal inert gas welding on the corrosion and mechanical behaviour of AA6061 T6, International Journal of Electrochemical Science, Vol. 9, pp. 1087-1101.

Malviya R. and Pratihar D.K., 2011, Tuning of neural networks using particle swarm optimization to model MIG welding process, Swarm and Evolutionary Computation, Vol. 1, No. 4, pp. 223-235.

Moshat S., Datta S., Bandyopadhyay A. and Pal P.K., 2010, Parametric optimization of CNC end milling using Entropy measurement technique combined with grey Taguchi method. International Journal of Engineering, Science and Technology, Vol. 2, pp. 1-12.

Murugan N. and Parmar R.S., 1994, Effects of MIG process parameters on the geometry of the bead in the automatic surfacing of stainless steel, Journal of Materials Processing Technology, Vol. 41, pp. 381-398.

Patel C.N. and Chaudhary S., 2013, Parametric optimization of weld strength of metal inert gas welding and tungsten inert gas welding by using analysis of variance and grey relational analysis, International Journal of Research in Modern Engineering and Emerging Technology, Vol. 1, No. 3, pp. 48-56.

Patil S. R., Waghmare C. A., 2013, Optimization of MIG welding parameters for improving strength of welded joints. International Journal of Advanced Engineering Research and Studies, Vol. 2. pp. 14-16.

Scotti A., Ponomarev V. and Lucas W., 2012, A scientific application oriented classification for metal transfer modes in GMA welding, Journal of Materials Processing Technology, Vol. 212, No. 6, pp. 1406-1413.

Shahi A.S. and Pandey S., 2008, Modelling of the effects of welding condition on dilution of stainless steel claddings produced by gas metal arc welding procedures, Journal of Materials Processing Technology, Vol. 196, Nos. 1-3, pp. 339-344.

Shih J.-S., Tzeng Y.-F. and Yang J.-B., 2011, Principal component analysis for multiple quality characteristics optimization of metal inert gas welding aluminium foam plate, Materials and Design, Vol. 32, No. 3, pp. 1253-1261.

Sreeraj P., Kannan T. and Maji S., 2013, Optimization of GMAW process parameters using particle swarm optimization, ISRN Metallurgy, Volume 2013, 10p., http://dx.doi.org/10.1155/2013/460651. 
Suban M. and Tusek J. (2001). Dependence of melting rate in MIG/MAG welding on the type of shielding gas used, Journal of Materials Processing Technology, Vol. 119, Nos. 1-3, pp. 185-192.

Tay K.M. and Butler C., 1997, Modelling and optimizing of a MIG welding process- A case study using experimental designs and neural network, Quality and Reliability Engineering International, Vol.13, pp. 61-70.

Tusek J., Kampus Z. and Suban M., 2001, Welding of tailored blank of different materials, Journal of Materials Processing Technology, 180-184.

Tsao C.C. (2009). Grey Taguchi methods to optimize the milling parameter of aluminium alloy, International Journal of Advanced Manufacturing Technology, Vol. 40, pp. 41-48.

Tosun N. (2006). Determination of optimum parameters for multi performance characteristics in drilling by using grey relational analysis, International Journal of Advanced Manufacturing Technology, Vol.28, pp. 450-455.

Wen K.L, Chang T.C. and You M.L., 1998, The grey entropy and its application in welding analysis. IEEE International Conference on System Manufacturing and Cybernetic, Vol. 2, pp. 1842-1844.

Wu C. S. 1992, Computer simulation of three-dimensional convection in travelling MIG weld pools, Engineering Computation, Vol. 9, pp. 529-537.

\section{Biographical notes}

Mr. Vedansh Chaturvedi is Assistant Professor in the Department of Mechanical Engineering, Madhav Institute of Technology and Science Gwalior, India. He has more than 06 years of experience in teaching and research. His current area of research includes Multi-criteria DecisionMaking, Neural Networks, and Non-traditional Optimization and Simulation. He has published more than thirty five papers in referred international journals. He has also presented more than 15 research articles in national and international conferences. He has received Madhya Pradesh young scientist award for outstanding research paper in 2014.

Ms. Rani Jatav is a final year student of stream M.Tech. (Production) in Mechanical Engineering Madhav Institute of Technology and Science Gwalior, India. She is pursuing his thesis work on optimization of MIG welding process parameters. Her current area of research includes DoE, Multivariate Analysis and Optimization Techniques. She has published one journal papers and presented two papers in international conferences.

Received June 2016

Accepted July 2016

Final acceptance in revised form August 2016 